\title{
AVALIAÇÃO FORMATIVA NA EDUCAÇÃO INCLUSIVA
}

\author{
Stephânia Cottorello VITORINO ${ }^{1}$ \\ Sonia Maria Duarte GREGO ${ }^{2}$
}

Resumo: Busca-se neste trabalho compreender como tem sido articulada a proposta da educação inclusiva e a avaliação no interior da escola, mais precisamente com o instrumento portfólio denominado como instrumento da avaliação formativa com os alunos com deficiência intelectual do ensino fundamental I, em uma escola da Rede Municipal do interior de São Paulo. A pesquisa da qual se origina o presente estudo está em andamento. A proposta de trabalho consistiu-se em realizar um estudo qualitativo de natureza empírica interpretativa, na linha da hermenêutica crítica. Nesta abordagem a pesquisa envolveu dois procedimentos de análise: análise documental e análise interpretativa crítica das produções dos alunos com deficiência intelectual na avaliação formativa através de portfólios no cotidiano da escola. Dentre o material já estudado sobre a avaliação pode-se verificar que se mostra relevante pela possibilidade de discutir vários aspectos e formas da avaliação formativa como um instrumento que pode facilitar e enriquecer a ação da proposta inclusiva nas escolas de Rede Pública Municipal sob a forma de parceria colaborativa, o que poderá favorecer o aprimoramento da prática docente com ação - reflexão - ação.

Palavras-chave: Educação inclusiva. Avaliação formativa. Deficiência intelectual.

\section{INTRODUÇÃO}

Para Gadotti e Romão (1994), a avaliação é inerente e imprescindível, durante todo processo educativo que se realize em um constante trabalho de ação-reflexão, porque educar é fazer ato de sujeito, é problematizar o mundo em que vivemos para superar as contradições, comprometendo-se com esse mundo para recriá-lo constantemente.

Observamos, assim, a necessidade de a avaliação ser formativa e transformada para atender as reais necessidades da aprendizagem do aluno, como afirma Perrenoud (1999, p.103), “[...] é formativa toda avaliação que ajuda o aluno a aprender a se

\footnotetext{
${ }^{1}$ Mestre em Psicologia. USP - Universidade de São Paulo. Doutoranda do Programa de Pós Graduação em Educação Escolar. UNESP - Universidade Estadual Paulista - Campus de Araraquara. Araraquara SP - Brasil. 14800-91 - stephaniacv@yahoo.com.br.

${ }^{2}$ Professora Adjunto do Departamento de Didática- Faculdade de Ciências e Letras da UNESP. Docenteorientadora do Programa de Pós-Graduação em Educação Escolar e Coordenadora do Grupo de Pesquisa Avaliação e Políticas Educacionais. UNESP - Universidade Estadual Paulista Júlio Mesquita Filho Campus de Araraquara. Araraquara - SP - Brasil.14800-91 - sonya.grego@gmail.com.
} 
desenvolver, ou melhor, que participa da regulação das aprendizagens e do desenvolvimento no sentido um projeto educativo".

Neste contexto, não importa quais os instrumentos avaliativos que o educador irá utilizar para fazer uma avaliação formativa e sim a forma que irá extrair os resultados e adaptá-los a sua prática ao encontro das necessidades do aluno, podendo ser seus instrumentos: a prova, testes, portfólio, observações de comportamento diante de determinada tarefa. Observa-se a necessidade de romper o sentido de avaliação em juízo de valor que está historicamente enraizada em nossa cultura escolar, em que o objetivo maior é a memorização, a classificação, a seleção, a criação de hierarquias, exclusão e certificação.

Como afirma Perrenoud (1999, p.79):

\begin{abstract}
A avaliação é formativa porque é uma avaliação que objetiva melhorar a formação; sua preocupação não é classificar, dar notas, punir ou recompensar, mas ajudar o aluno a aprender. Uma avaliação que permita aos alunos identificar seus erros, acertos e lacunas; e aos mestres destacar os ganhos e as dificuldades de cada aluno para poder ajudá-los a progredir mais.
\end{abstract}

A avaliação formativa fundamenta-se na observação e no registro do desenvolvimento dos alunos, em seus aspectos cognitivos, afetivos e relacionais, passa a ser uma avaliação contínua e diária, o que possibilita ajustar as necessidades detectadas por ela aos ajustes reais do currículo da sala de aula, partindo do pressuposto de que a avaliação formativa tem a função de agir; é diagnóstica e sistemática e é o eixo do processo de ensino-aprendizagem; permite rever todos os passos do planejamento isto é, se os padrões pretendidos são adequados, se o tempo pensado para aprendizagem é suficiente, se as tarefas propostas para aprendizagem foram funcionais se os materiais didáticos são apropriados, se a relação aluno-professor é produtiva, etc.

Se sabemos que o aluno com deficiência intelectual apresenta um desenvolvimento diferenciado a nível cognitivo na sua maneira de apreender, dentro de um tempo diferente dos demais pares de sua idade, necessitando de recursos diferenciados e com intervenções planejadas e constantes para que aconteça inclusive uma resposta, realmente nos deparamos com uma avaliação "contraditória e injusta" nos dizeres de Grego (2013).

Mas, a construção de ações apontadas a partir dos resultados das avaliações externas é algo complexo que remete à insegurança, pois o desenvolvimento de uma 
avaliação formativa, de acompanhamento do desenvolvimento do aluno, que respeite sua cultura primeira. Envolve integrar a avaliação como parte do processo de ensino “[...] significando que a avaliação se insere na interação professor-aluno-conhecimento e nas interações entre os alunos, a orientar um processo de diferenciação do ensino e de diferenciação da aprendizagem". (GREGO, 2013, p.97).

Envolve, ainda, como esclarece Grego (2013, p. 97) “[...] tornar o aluno autor de sua própria aprendizagem, no sentido de estimulá-lo a se envolver em um processo de autorregulação, de desenvolvimento de suas capacidades metacognitivas, em um constante processo interativo com o professor e com seus pares".

É com essa finalidade e com essa intenção que a avaliação formativa, seja ela com o uso de portfólio e/ou outros instrumentos que viabilizam o objetivo de registrar o desenvolvimento do aluno é que teremos uma avaliação a favor do aluno, não no sentido de favorecer esse aluno em questões de mérito, mas sim favorecer e fornecer uma aprendizagem que realmente acompanhe o desenvolvimento desse aluno.

Grego (2013) apresenta características essenciais para que uma avaliação formativa tenha como objetivos ajudar o aluno a aprender e o professor a ensinar, sendo elas:

1. Integração da avaliação formativa em cada atividade de ensino, significando que a avaliação se insere na interação professor-alunoconhecimento e nas interações entre os alunos, a orientar um processo de diferenciação do ensino e de diferenciação da aprendizagem;

2. A avaliação visa tornar o aluno autor de sua própria aprendizagem, no sentido de estimulá-lo a se envolver em um processo de autorregulação, de desenvolvimento de suas capacidades metacognitivas, em um constante processo interativo com o professor e com seus pares;

3. Adoção do conceito de regulação das aprendizagens, que envolve feedback mais adaptação do ensino e da aprendizagem (em contraposição ao conceito de recuperação das dificuldades de aprendizagem - feedback mais correção);

4. Ressignificação do conceito de regulação, que passa a compreender tanto formas de avaliação para diagnóstico e acompanhamento dos alunos como formas de intervenção para orientar o pensamento dos alunos na construção de sua aprendizagem e que passa a envolver duas novas modalidades distintas de regulação: regulação interativa e regulação proativa, além da regulação retroativa, própria do modelo de avaliação formativa no enfoque positivista. (GREGO, 2013, p.97).

Diante do que foi apresentado pela autora, observa-se que há como praticar uma avaliação formativa, porém esta precisa ser ressignificada em seu conceito, e ser 
compreendida em suas múltiplas ações, sendo elas diagnóstica e interventiva, trabalhando com conceitos de regulação de aprendizagem após a identificação da dificuldade de aprendizagem, tornando o aluno como agente participativo de sua aprendizagem. Nas palavras de Perrenoud (1999, p.89):

\begin{abstract}
A ideia de avaliação formativa sistematiza esse funcionamento, levando o professor a observar mais metodicamente os alunos, a compreender melhor seus funcionamentos, de modo a ajustar de maneira mais sistemática e individualizada suas intervenções pedagógicas e as situações didáticas que propõe, tudo isso na expectativa de otimizar as aprendizagens.
\end{abstract}

Nesse contexto, observa-se a necessidade de uma mudança na proposta pedagógica que motive o olhar individualizado para cada aluno, com seus avanços e dificuldades, porém com possibilidades detectadas que almejem a retomada do conteúdo não apreendido e do avanço ao conteúdo já assimilado, oportunizando possibilidades para que esse aluno consiga avançar dentro dos objetivos e metas estabelecidas para ele.

Gardner (1995, p.159) considera dois momentos importantes na atuação do professor, para acompanhar o processo desenvolvimento do aluno "[...] gostaria de ver as escolas procurando evidências de várias inteligências, através da coleta de informações (a partir do próprio aluno e de outras pessoas) sobre os tipos de projeto em grande escala nos quais o aluno se envolve e os tipos de produtos que foram executados.

Gardner (1995, p.160) descreve a atuação do professor como:

[...] eu gostaria de ver os professores da universidade adotarem uma gama mais ampla de instrumentos de avaliação. Os projetos (e não apenas as provas do ano escolar) deveriam ser uma opção regular para os alunos, e todos deveriam ter oportunidade de executar e depois avaliar (e ter avaliados) alguns de seus próprios projetos.

O autor considera a prática do portfólio como sendo coleções de projetos, e que constituíram uma parte reveladora do dossiê de cada aluno (GARDNER, 1995).

Entretanto, nota-se que para melhorar a avaliação há necessidade de tocar no conjunto do sistema didático, do sistema escolar e do sistema político que também rege o sistema educacional brasileiro. Neste sentido, observa-se que a avaliação formativa, é um componente indispensável dentro do processo de uma pedagogia diferenciada, suas 
múltiplas funções designam em regular e orientar o processo de ensino-aprendizagem, a avaliação passa a ter outra característica, deixa de ser um fim em si mesma e passa a ser um meio de diagnosticar, regular e orientar.

Hoffmann (1995, p.18), descreve:

[...] a avaliação é a reflexão transformadora em ação. Ação, essa, que nos impulsiona a novas reflexões. Reflexão permanente do educador sobre sua realidade e acompanhamento, passo a passo, do educando, na sua trajetória de construção do conhecimento. Um processo interativo, através do qual educandos e educadores aprendem sobre si mesmos e sobre a realidade escolar no ato próprio da avaliação.

Para Hadji (1994) a avaliação é um meio de comunicação social e deve fornecer ao aluno informações que ele possa compreender e que lhe sejam úteis. "Para ser um ato de comunicação útil, a avaliação deve retomar a ligação com o produtor, e dizer-lhe alguma coisa acerca da sua produção que lhe permita progredir com vista a melhores produções". (HADJI, 1994, p.108).

Através do objetivo da avaliação que é medir habilidades e competências e olhar para o produto do produtor, a avaliação precisa fazer uma leitura que traga elucidação e orientação que norteie o desenvolvimento e o aperfeiçoamento das habilidades e das competências avaliadas do próprio produtor, que se dará somente a partir da comunicação e de estratégias que lhe permitam avançar do ponto ao qual foi avaliado. Torna-se compreendida à medida que devolve ao avaliado e a quem está possibilitando seu aprendizado, no caso, o professor, informações cabíveis a reestruturação do seu planejamento e o professor enquanto norteador de tal ação a possibilidade de retomada em conteúdos não compreendidos pelo aluno, sem descaracterizar, portanto, a avaliação em sua função e sem estigmatizar o aluno pelo seu desempenho na prova. Sendo uma rotina da própria ação do professor a avaliação para se obter meios de se avançar ou de se recuar em conteúdos trabalhados com o aluno.

Alunos com deficiência intelectual apresentam dificuldade em seu percurso escolar em atingir os objetivos propostos pelo currículo escolar da maneira como é apresentado, sem adaptações nas estâncias apresentadas pelos Parâmetros Curriculares Nacionais da Educação Especial (BRASIL, 1998), o fracasso escolar e o resultado insatisfatório das avaliações acabam sendo atribuído à questão biológica do aluno e não à falta de adaptações que acontecem na escola e nos sistemas e quem responde pelo fracasso é somente o aluno. Os elementos a serem considerados nas Adaptações 
Curriculares são cuidadosamente expressos no texto das Diretrizes Curriculares para Educação Especial na Educação Básica:

[...] flexibilização e adequações curriculares, que considerem o significado prático e instrumental dos conteúdos básicos, metodologias de ensino e recursos didáticos diferenciados e processos de avaliação adequados ao desenvolvimento dos alunos que apresentam necessidades educacionais especiais, em consonância com o projeto pedagógico da escola da escola [...]. (BRASIL, 2001, p.47).

Sabemos o quanto o currículo da maneira como é apresentado, ressaltando as adaptações devidas para que se possibilite o desenvolvimento da criança com deficiência, gera discussões e também conflitos, porém é uma estratégia que vai além de simples adaptações, tais estratégias revelam respeito às condições cognitivas, aos limites e as possibilidades de cada aluno. Como vimos às adaptações nas avaliações também é citada em vários documentos que se propaga a educação inclusiva e é com este olhar e com esta ação que poderemos falar em educação inclusiva.

Após nos reportarmos à avaliação formativa como sendo um instrumento de parâmetro ao professor na educação básica, faremos um estudo sobre como se processa a avaliação na educação inclusiva e para isso, nos atentaremos para grandes pesquisadores brasileiros que estudam a educação inclusiva.

Apesar de se falar a respeito das diferenças, sejam essas raciais, de gêneros e culturais, ainda se encontram enraizadas o caráter homogeneizador de lidar com as coisas e com as pessoas.

Segundo Fávero, Pantoja e Mantoan (2007, p.54), “[...] o processo de avaliação que é coerente com uma educação inclusiva acompanha o percurso de cada estudante a evolução de suas competências e conhecimentos".

Observa-se que a finalidade da avaliação na educação inclusiva é o de acompanhar o desenvolvimento do aluno em aspectos de conteúdos pedagógicos, afetivos e sociais. Fávero, Pantoja e Mantoan (2007, p.54), descreve o caráter da avaliação,

[...] muda-se o caráter da avaliação que, usualmente, é praticada nas escolas e que tem fins meramente classificatórios. A intenção dessa modalidade de avaliar é levantar dados para melhor compreensão do processo de aprendizagem e para o aperfeiçoamento da prática 
pedagógica. Para alcançar sua nova finalidade, a avaliação terá , necessariamente, de ser dinâmica, contínua, mapeando o processo de aprendizagem dos alunos em seus avanços, retrocessos, dificuldades e progressos.

Segundo Batista e Mantoan (2007, p.19) “[...] a avaliação dos alunos com deficiência mental visa ao conhecimento de seus avanços no entendimento dos conteúdos curriculares durante o ano letivo de trabalho, seja ele organizado por série ou ciclos.

A avaliação formativa exige das instituições escolares muito trabalho e disciplina, mais dedicação, mais observação, mais reflexão e menos influências externas. Por isto, neste estudo destacamos a avaliação formativa, através do instrumento portfólio, que tem como objetivo proporcionar o acompanhamento do aluno diariamente, pautado em proporcionar reflexões sobre a prática docente o que possibilita a construção do conhecimento do aluno e do docente. Parte de anotações feitas das observações dos alunos e dos trabalhos, das atividades, dos exercícios, das produções por eles realizadas.

Para Sá-Chaves (2000), o portfólio evidencia ao mesmo tempo, tanto para o educando quanto para o educador, processos de autorreflexão. São laboratórios nos quais os estudantes constroem significados a partir de sua experiência acumulada. É um resumo da trajetória de aprendizagem.

Esta prática de avaliação ainda não é comum entre os docentes dos sistemas educacionais brasileiros, talvez pela falta de orientação em como proceder e organizar tal documento e também por ser minucioso o que requer tempo e dedicação para fazêlo.

A Lei de Diretrizes e Bases da Educação Nacional (BRASIL, 1996) trata a avaliação escolar nos seguintes termos:

Artigo 24, Inciso V: A verificação do rendimento escolar observará os seguintes critérios: a) avaliação contínua e cumulativa do desempenho do aluno, com prevalência dos aspectos qualitativos sobre os quantitativos e dos resultados ao longo do período sobre os de eventuais provas finais. (BRASIL, 1996, p.12).

As avaliações aplicadas nas escolas são resumidamente transformadas a apenas em obter resultados, são consideradas avaliações formais onde muda apenas a forma de apresentação sendo testes e provas escritas, com a única preocupação nos méritos 
alcançados e também aos não alcançados, prevalecendo desta maneira o aspecto quantitativo sobre o qualitativo, não seguindo os termos da Lei de Diretrizes e Bases da Educação Nacional n. 9394/96 (BRASIL, 1996), deixando de observar o rendimento escolar do aluno ao longo do período escolar.

Observamos, assim, a necessidade da avaliação ser formativa e transformada para atender as reais necessidades da aprendizagem do aluno, como afirma Perrenoud (1999, p.103), “[...] é formativa toda avaliação que ajuda o aluno a aprender a se desenvolver, ou melhor, que participa da regulação das aprendizagens e do desenvolvimento no sentido um projeto educativo".

Considerando este contexto, o presente artigo propõe levantar e apresentar subsídios para uma reflexão sobre a relevância das avaliações como instrumento de grande potencial para a educação, superando a cultura internalizadora do conceito de avaliação como estigmatizadora e classificadora.

\section{Objetivos}

Para atender os objetivos desta pesquisa, que se baseia na experiência em avaliação interna através de registros diários através do portfólio, das avaliações adaptadas ao conteúdo desenvolvido com o aluno com deficiência intelectual e relatórios bimestrais e semestrais sobre desenvolvimento do aluno realizada pela gestão da Rede Municipal de Ensino de uma cidade do interior do estado de São Paulo, entre os anos de 2009 a 2013, que foi o período em que a rede municipal de educação começou a receber alunos com deficiências das instituições especializadas, tomaram-se as seguintes decisões metodológicas:

- Analisar a importância da avaliação formativa, no ensino fundamental, como instrumento de grande potencial para educação;

- Verificar como está sendo utilizados os resultados das avaliações internas na prática docente e como é utilizado para o desenvolvimento da aprendizagem dos alunos com deficiência intelectual;

- Averiguar junto à equipe da escola como está se articulado para ser considerada uma escola que atenda a todos.

Analisar e teorizar essas concepções e práticas, evidenciando as contribuições que oferecem para o aperfeiçoamento do processo de avaliação no ensino e pelas transformações das práticas pedagógicas que as avaliações formativas podem oferecer. 


\section{Metodologia}

A proposta de trabalho consistiu-se em realizar um estudo qualitativo de natureza empírica interpretativa, na linha da hermenêutica crítica, como proposto por Kincheloe e MacLaren (2006). Nesta abordagem a pesquisa envolveu dois procedimentos de análise: análise documental e análise interpretativa crítica das produções dos alunos com deficiência intelectual na avaliação formativa inclusiva através de portfólios no cotidiano da escola. Na análise documental utilizou-se como fontes primárias, documentos referentes a Instrução CGEB de 14 de Janeiro de 2015 (dispõe sobre a escolarização de alunos com deficiência intelectual (DI) de que trata a Resolução SE no 61/2014) (SÃO PAULO, 2014), bem como normas e diretrizes emanadas de órgãos superiores e como fontes secundárias estudos e pesquisas sobre educação inclusiva de alunos com deficiência, sobre avaliação da aprendizagem, avaliação formativa, em especial de alunos com deficiência intelectual.

\section{Discussão}

Ainda que parciais, os resultados do estudo têm possibilitado averiguar que a avaliação no interior da escola é algo que ainda traz questionamentos, inseguranças e impotência diante da ação de como elaborar uma avaliação que norteie a prática do professor com o aluno com deficiência intelectual. Diante do que é proposto pelos documentos oficiais na garantia de uma escola inclusiva com qualidade mediante o respeito ao desenvolvimento, ao ritmo, ao tempo que cada aluno tem para avançar nos conteúdos propostos pela escola e a adaptação nas atividades. Contemplando informações através do instrumento avaliativo formativo denominado como portfólio voltados especificamente a acompanhar o desenvolvimento dos alunos com deficiência intelectual juntamente com os relatórios de desenvolvimento bimestrais e semestrais desses alunos. Temas importantes foram preliminarmente extraídos das análises iniciais já elaboradas, dentre os quais destacaram-se diversos questionamentos que o estudo pretende analisar em profundidade ao longo do seu desenvolvimento. De forma sucinta, os primeiros resultados permitem observar a necessidade de investigar as relações pressupostas entre: a) a percepção dos professores com relação à importância de uma avaliação que norteie a sua prática, que acompanhe e registre o desenvolvimento dos alunos com deficiência intelectual; b) a avaliação formativa como um instrumento necessário, porém com necessidade de orientação aos professores em sua execução para realmente atender as propostas de educação inclusiva atualmente vigentes; c) uma 
proposta de avaliação formativa para todos os alunos como um instrumento de acompanhamento do desenvolvimento escolar.

\title{
Considerações finais
}

O presente estudo encontra-se em andamento. Acreditamos que esse trabalho trará contribuições para o campo da Educação Inclusiva, portanto para todos. Além disso, o estudo poderá contribuir para elucidar quais são as percepções dos professores participantes a respeito da avaliação formativa na perspectiva da Educação Inclusiva, o que propiciará um melhor conhecimento da prática pedagógica e um aprofundamento de questões essenciais a respeito à adaptação da avaliação e a reflexão sobre a prática da avaliação formativa na construção do processo pedagógico do professor e no respeito ao desenvolvimento do aluno com deficiência. A pesquisa também se mostra relevante pela possibilidade de discutir vários aspectos e formas da avaliação formativa como um instrumento que pode facilitar e enriquecer a ação da proposta inclusiva nas escolas de Rede Pública Municipal sob a forma de parceria colaborativa, o que poderá favorecer o aprimoramento da prática docente com ação - reflexão-ação.

\section{EVALUATION INFORMATION ON INCLUSIVE EDUCATION}

\begin{abstract}
This work seeks to understand how has been articulated the proposal of inclusive education and evaluation within the school, but precisely with the instrument portfolio termed as instrument of formative assessment with students with intellectual disabilities of elementary school I in a public school from São Paulo state. The research of which originates from the present study is in progress. The proposed work consisted in carrying out a qualitative study of empirical nature, in line with the interpretative critical hermeneutics. In this approach the research involved two analysis procedures: document analysis and critical interpretative analysis of the productions of the students with intellectual disabilities in formative assessment through portfolios in the everyday life of the school. Among the material already studied about the assessment can verify that is relevant for the opportunity to discuss various aspects and ways of formative assessment as a tool that can facilitate and enrich the action of inclusive schools proposal of Municipal Public Network in the form of collaborative partnership, which can encourage the improvement of the teaching practice with action-reflection-action.
\end{abstract}

Key words: Inclusive education. Formative assessment and intellectual disabilities.

\section{REFERÊNCIAS}


BATISTA, C. A. M.; MANTOAN, M. T. E. Atendimento educacional especializado em deficiência mental. In: GOMES, A. L. L. et al. Deficiência mental. São Paulo: MEC/SEESP, 2007. p.13-22. (Atendimento Educacional Especializado).

BRASIL. Ministério da Educação. Diretrizes nacionais para a educação especial na educação básica. Brasília: MEC; SEESP, 2001.

Lei no 9394/ 20.12.96. Lei de Diretrizes e Bases da Educação Nacional. Brasília: Saraiva, 1996.

Parâmetros Curriculares Nacionais: adaptações curriculares. Brasília: MEC; SEESP 1998.

FÁVERO, A. G.; PANTOJA, L. M. P.; MANTOAN, M. T. E. Atendimento educacional especializado: aspectos legais e orientação pedagógica. Brasília: MEC/SEESP, 2007.

GADOTTI, M.; ROMÃO, J. E. Educação de jovens e adultos: teoria, prática e proposta. 1.ed. São Paulo: Cortez: Instituto Paulo Freire, 1994. (Guia da Escola Cidadão, 5).

GARDNER, H. Inteligências múltiplas: a teoria na prática. Porto Alegre: ARTMED, 1995.

GREGO, S. M. D. Os múltiplos sentidos e caminhos da avaliação educacional. In: PróReitoria de Graduação: Univesp. (Org.). Caderno de formação: formação de professores v.3. São Paulo: Cultura Acadêmica: Universidade Estadual Paulista, 2013. p.17-33. Disponível em: <http://www.acervodigital.unesp.br/bitstream/123456789/65805/1/u1_d29_v3_t01.pdf> Acesso em: 26 abr. 2016.

HADJI, C. A avaliação, regras do jogo. Das intenções aos instrumentos. Portugal: Porto Editora, 1994.

HOFFMAN, J. Avaliação: mito \& desafio. Uma perspectiva construtivista. Porto Alegre: Educação e Realidade, 1995.

KINCHELOE, J.; MCLAREN, P. Repensando a teoria crítica e a pesquisa qualitativa. In: DENZIN, N. K.; LINCOLN, Y. S. (Org.) O planejamento da pesquisa qualitativa: teorias e abordagens. 2.ed. Porto Alegre: ARTMED, 2006. p.281-313.

PERRENOUD, P. A pedagogia na escola das diferenças: fragmentos de uma sociologia do fracasso. Tradução de C. Schilling. Porto Alegre: ARTMED, 1999.

SÁ-CHAVES, I. Portfólios reflexivos: estratégia de formação e de supervisão. Aveiro: Universidade, 2000.

SÃO PAULO (Estado). Resolução SE 61 de 11/11/2014. Dispõe sobre a educação especial nas unidades escolares da rede estadual de ensino SP. Diário Oficial Poder Executivo do Estado de São Paulo, São Paulo, seção 1, 12 nov. 2014. 